\title{
Exploring beneath the PIG Ice Shelf with the Autosub3 AUV
}

\author{
S. D. McPhail, M. E. Furlong, M. Pebody, J.R. Perrett, P. Stevenson, A. Webb, D. White, \\ National Oceanography Centre, Southampton, UK.
}

\begin{abstract}
On 31st January 2009, two numbers: "range and bearing" flashing up on a laptop screen, indicated that Autosub3 had returned from its last mission beneath the Pine Island Glacier (PIG) Ice Shelf in the Western Antarctic. The Autosub technical team from NOCS, Southampton, onboard the US ice breaker Nathanial B Palmer breathed a collective sigh of relief. Any significant technical failure would have resulted in total loss of the multi million Euro Autonomous Underwater Vehicle with no hope of recovery from $60 \mathrm{~km}$ into the ice shelf cavity. This was the last of six successful missions to investigate the shape the ice shelf, the sea bed bathymetry, the currents and the physical oceanography within the ice cavity. Each are vital to understanding the interaction between the sea water and the ice shelf, and quantifying whether the melting rate is changing. During the cruise, Autosub3 had run beneath the ice for almost 4 days and for $510 \mathrm{~km}$.
\end{abstract}

Autosub3 had been exploring the Pine Island Glacier, a floating extension of the West Antarctic ice sheet, as part of an international team effort lead by Dr Adrian Jenkins of the British Antarctic Survey and Dr Stanley Jacobs of the Lamont-Doherty Earth Observatory, New York. Autosub3 was launched from the Nathaniel B Palmer, an American icebreaker, as part of the two month cruise to investigate the oceanography, biology and glaciology of the Southern Amundsen Sea.

This paper will concentrate on the technical aspects of the Autosub3 vehicle and its missions under the PIG, and seek to answer a number of questions: How did the AUV successfully dead reckon navigate for over 24 hours, and return accurately to the rendezvous point? How did we cope with the possibility of ice bergs or sea ice drifting over the recovery position? How did Autosub3 (almost always) avoid collision with the jagged ice shelf above, or the unknown depths of the seabed? How did we communicate with the vehicle at the start and the end of missions? How did we manage risk, and prior to the cruise, what modifications and testing did we apply to the AUV to improve the overall reliability? What measures did we take during the cruise to further improve our chances of a successful outcome ?

The paper will outline the history of the use of AUVs for polar science. Results from the recent cruise will be presented showing the actual mission tracks, with the echo sounder isonified ice draft and seabed. Not all went completely to plan: the paper will also describe the events of Autosub's close scrape on its $4^{\text {th }}$ mission under the PIG.

This work was funded by the Natural Environment Research Council, UK and the National Science foundation, USA.

\section{INTRODUCTION}

\section{A) AUV Operations Under Ice}

AUVs have some clear disadvantages compared traditional, ship based methods for conducting oceanographic research. Without access to atmospheric oxygen, and hence typically using either primary or rechargeable battery technology, they are severely limited in their stored energy capacity compared to surface craft, resulting in either limited range or rather slow operating speed. There are also significant inherent risks of total loss associated with deploying any instrument without a tether from a ship, and recovery of the rather fragile AUVS onto a research ship can be hazardous if not dangerous in anything other than ideal sea states. As rather complicated examples of technology, and produced in relatively small numbers, they tend to be expensive.

So why use this expense, fragile, slow moving, risky technology?

One obvious niche area for AUVs is the acquisition of oceanographic data in areas which are either difficult or impossible to access by other means. The deep ocean is one such area. AUVs are well adapted to carrying out simple area surveys, and navigation technology has progressed to a point where the required repeatability and absolute accuracy can often be achieved. Another niche area is very long duration, long distance oceanographic survey. By going very slowly, and tightly controlling the energy used by the sensors, AUVs can run for months and cross ocean basins. Currently, only ocean gliders operate in this mode.

The subject of the paper concerns a third niche area for AUVs: operation of an AUV under sea ice (which may have limited or no accessibility by a research ship), or more particularly under an ice shelf (which is almost totally inaccessible by other means).

The earliest recorded AUV operations carried out under ice, were by the UARS (Unmanned Arctic Research Vehicle) AUV in 1972. UARS was a development of the SPURV AUV series, developed from the 1950's by the University of Washington's Applied Physics Laboratory. In a project funded by the US Office of Naval Research, the $410 \mathrm{~kg}$ AUV, fitted with pencil beam upward looking sonars, and deployed through an ice hole, obtained ice thickness data near the ice island T-3 in the Beaufort sea.

Twenty years later, in 1992, the University of Washington's Applied Physics Laboratory, as part of the Winter Lead Experiment (LeadEx) in the Beaufort Sea, deployed the very 
small $(9.5 \mathrm{~kg})$ Autonomous Conductivity Temperature Vehicle (ACTV) under and around ice leads for a few $\mathrm{km} \mathrm{[2].} \mathrm{Another}$ example of the use of an AUV for process flow study, was the measurement of turbulence, salt and heat fluxes using a modified REMUS AUV in August 1998, as part of the Surface Heat Balance of the Arctic Ocean (SHEBA) program [3].

But still outstanding in its achievement in terms of risk, technical difficulty, distance travelled, and navigation performance at extreme latitudes was the Spinnaker project,

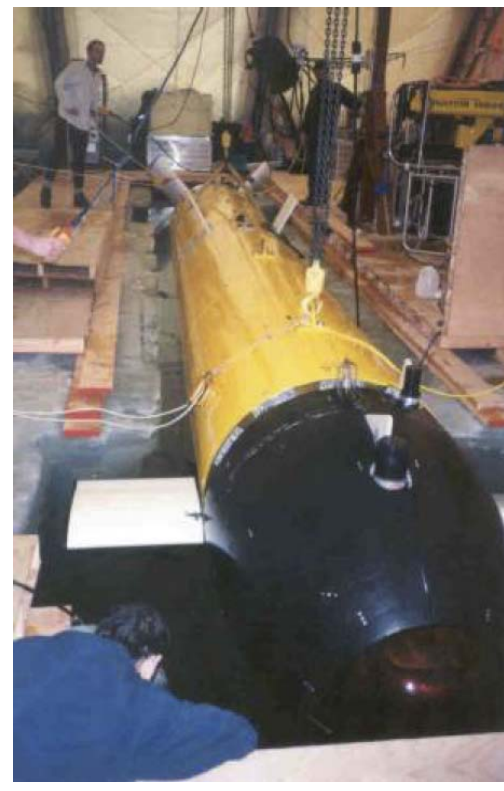

Figure 1. The Theseus AUV being lowered into an ice hole in at the start of a $400 \mathrm{~km}$ round trip the Canadian Arctic.

This is still a record for an under ice mission employing the 9.6 tonne International Submarine Engineering,

Theseus Vehicle, (Fig.1) which, in April 1996, succeeded in laying 175 $\mathrm{km}$ of optical fibre under fast ice in the high Canadian Arctic, north of Ellesmere Island (85.5 degrees Latitude), threading the fibre through a $200 \mathrm{~m}$ wide loop at the destination and then returning home, to be recovered (using a ROV to attach a line) through a $2 \mathrm{~m}$ by $13 \mathrm{~m}$ hole in the ice at the Ice Camp Knossos near Jolliffe Bay[4].

In 2001 the first AUV imagery of the underside of sea ice was obtained by a Maridan Martin 150 AUV fitted with sidescan sonar, in the winter marginal ice zone of the East Greenland current [5]. Although each run was only a few $\mathrm{km}$ in length, the project showed the potential of using an AUV under ice, and highlighted some of the problems of recovery in these conditions (Fig. 2).

Also in 2001, engineers from MBARI tested the Dorado AUV in the Arctic, north and west of Svalbard, evaluating the vehicle systems and particularly the performance of Inertial Navigation Systems at high latitude [6], also obtaining measurements of ice thickness using a modified ASL, Ice Profiling Sonar.

More recently, in the summer of 2007, as part of the Arctic Gakkel Vents Expedition (AGAVE), WHOI, with the PUMA and JAGUAR AUVS, conducted deep water (up to $4062 \mathrm{~m}$ ) under sea ice missions to detect hydrothermal plumes and photograph the seafloor. With a maximum endurance of 24 hours, and a slow descent rate of less than $1000 \mathrm{~m}$ per hour 30 , the survey time on the seafloor was limited to a few hours for the deepest dives. These are the deepest under ice AUV missions to date [7].

\section{B) The Autosub2 Program}

The Autosub AUVs have probably the most experience of operations in the polar regions, benefiting greatly from contiguous support from UK, Natural Environment Research Council (NERC) during the Autosub Under Ice (AUI) program 2001 to 2005. But Autosub's first under ice missions were actually funded as part of a previous NERC funded program (Autosub Science Missions). Valuable experience was gained in operating the AUV under sea ice in the Weddel sea, while

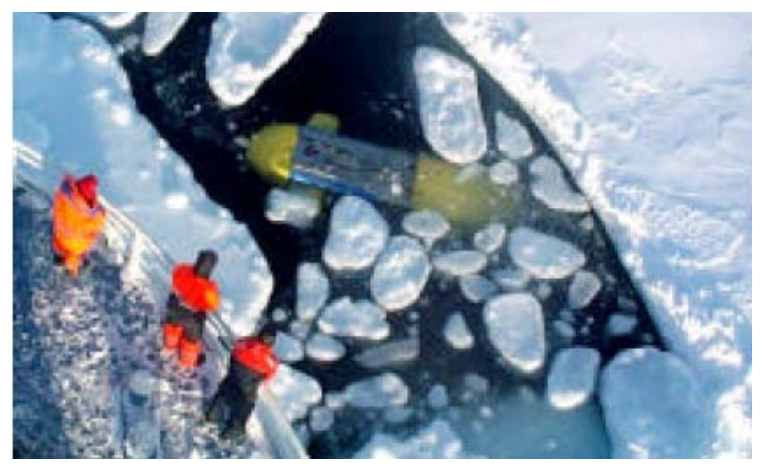

Figure 2. The recovery of the Martin 150 AUV onto the RV Lance in the East Greenland Current.

investigating the population of Antarctic Krill using sonar [8]. This early practical experience helped us to develop the AUV capabilities. For example, a (survived) collision with an iceberg provided an impetus to develop a collision avoidance system. As can be seen in Fig.3, for these early Antarctic missions, with no garage system for the AUV, we were forced to work with the AUV on deck. A less than ideal situation.

One of the high points for the AUI programme was in August 2004 when Autosub2 operated under fast sea ice off North East Greenland, for several ice thickness profiling missions [9]. On the return leg from one 24 hour mission, the collision avoidance behaviour was triggered due to a limited water column thickness event caused by coincident ice ridges and shallow water depth. The AUV successfully negotiated the obstruction, and returned to the recovery waiting position, at $50 \mathrm{~m}$ depth. But the AUV's problems were not over. Sea ice had blown over the recovery position, and hence it was necessary to use the AUV homing system to shepherd the AUV to an ice clear area where it could safely surface and be recovered onto the RRS James Clark Ross.

Six months later, in January 2005, Autosub2 had been shipped to the Antarctic. The target this time was the FilchnerRonne Ice Shelf in the Weddel sea. The surrounding sea ice was too thick for the RRS James Clark Ross to approach this ice shelf, and so the Fimbul Ice shelf, in the Lazareth sea, at near zero degrees longitude was targeted. It was here that Autosub2 carried out its first sub ice shelf mission, penetrating $30 \mathrm{~km}$ into the cavity with over $500 \mathrm{~m}$ of ice above. This single, twelve hour under ice mission, which ran close to the seabed on the way in, and tracked the ice while imaging with multibeam sonar the under ice surface on the way out, 
significantly changed our views about the sub-ice shelf environment, [10].

However, celebrations for this successful mission were short lived. Three days later Autosub2 was programmed to run on a similar track to its previous mission, the main difference being that the vehicle would profile to within $50 \mathrm{~m}$ of the under-ice and seabed surfaces on the outward leg, and follow the ice at a range of $100 \mathrm{~m}$ on the return leg. But six hours after launch, transmissions from the emergency beacon system, emanating

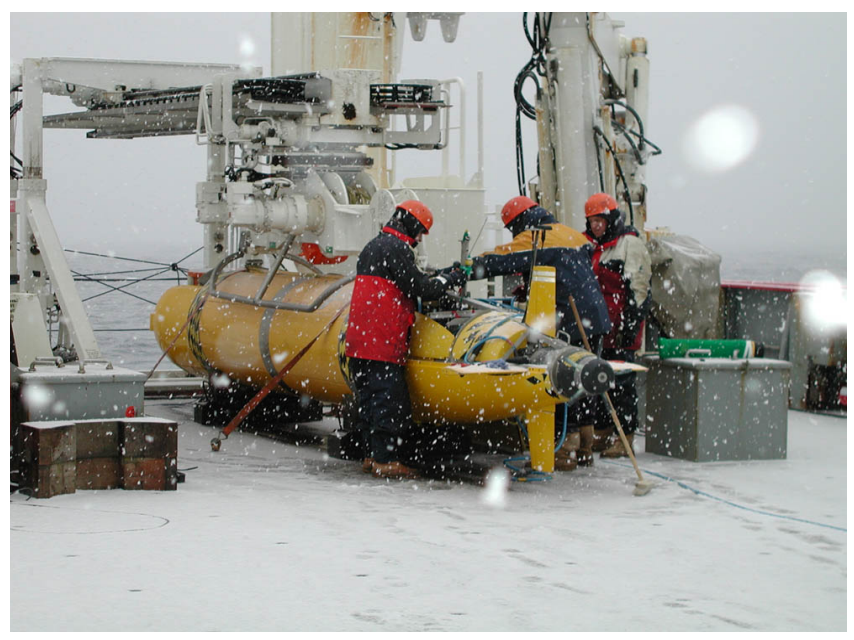

Figure 3. The first Autosub under ice operations where in the Weddel sea in early 2001 . We had no 'garage'.

from a position $15 \mathrm{~km}$ under the ice shelf, indicated the Autosub was stranded. Given its position, there was no hope of a successful recovery.

A thorough analysis of the loss was carried out, but due to lack of any detailed telemetry information, the likely cause for the loss can only be expressed in terms of probabilities [11]. The single most likely cause was considered to be a system power failure, as a result of hardware or a connector failure.

\section{The Design of Autosub3}

\section{A) Testing and Risk Analysis}

It had always been recognised that operations of an AUV under an ice shelf were a 'high risk - high return' activity, illustrated by the impracticality of obtaining insurance cover for the vehicle for under ice work. Hence funds (from NERC) had been made available for a replacement for Autosub2. The build of this vehicle had been started before the loss of Autosub2, and so in June 2005 we were able to carry out the preliminary field tests of the replacement AUV, Autosub3, on RRS Discovery. From then until the polar missions of early 2009, Autosub3 was tested for a total running period of over 20 days $(2800 \mathrm{~km})$, during five science and trials cruises.

The ensuing AUV fault records became the basis for both driving development of the vehicle systems, and for the production of a statistic fault model for the vehicle [12], which predicted the probability of loss of the AUV under an ice shelf as a function of such parameters as the distance run under an ice shelf, and the length of the missions. Such a model was central, both for providing the funding body (NERC), and the owner of the risk (director of NOCS) the information with which to make an informed decision as to whether the risk of a campaign was acceptable, but also as a tool for guiding decisions on modifications to the vehicle and the design of missions to reduce as far as practical the residual risk.

\section{B) AUV design for use under ice.}

\section{Changes for Autosub3}

Autosub3 is very similar is basic design to Autosub2, with some design changes implemented as a result of the vulnerabilities identified during the analysis of events surrounding the loss of Autosub2. For example, changes included:

- Separation of critical and non-critical power and network communications systems.

- Incorporation of greater redundancy for the critical power system bus and for the critical internal communications network.

- Provision of different mission contexts for the abort system (for example disabling the drop weight system when the vehicle is under ice).

\section{Autosub3 parameters}

The AUV is $6.8 \mathrm{~m}$ long and $0.9 \mathrm{~m}$ in diameter, with a form displacement of 3.5 tons, propelled by a brushless d.c. motor driving a twin bladed propeller. Energy is provided by $500 \mathrm{~kg}$ of manganese alkaline batteries, held in 4 carbon fibre composite pressure cases which span the central section of the vehicle. It is these pressure cases which limit the depth rating of the AUV to $1600 \mathrm{~m}$. The operating range of the vehicle is dependent upon the payload power, speed and the temperature of batteries. With a sensor configuration which includes the Simrad EM2000 multibeam sonar (using $120 \mathrm{~W}$ alone), and at a battery operating temperature of 5 Celsius, the range is 350 $\mathrm{km}$ at a speed of $1.5 \mathrm{~ms}^{-1}$.

\section{Control System}

The Autosub command control and mission management system is implemented on a distributed LonWorks [13] network of 12 processor nodes with additional processors being added as needed for varying sensor payloads. Autosub missions are specified in a text script format using event triggers, waypoint defined tracks, and either depth or altitude demands [14]. As an example, a mission element might trigger on a "got position" event and specify a new track consisting of two waypoints defined in latitude and longitude.

Sensors used for the control of the AUV (Fig. 4) are:

> $150 \mathrm{kHz}$ downwards looking Teledyne-RDI Workhorse Navigator ADCP providing Doppler bottom tracking navigation at up to $450 \mathrm{~m}$ range and providing altimeter data for terrain following flight.

$>300 \mathrm{kHz}$ upwards looking ADCP (with a range of 200m) for use as an overhead range sensor and also to allow Doppler 
tracking on overhead ice should the downwards ADCP be out of range.

$>$ Ixsea PHINS inertial navigation system integrated and mechanically coupled with the downwards looking ADCP. Typical navigational errors are of between $0.2 \%$ and $0.1 \%$ of distance travelled (with bottom tracking ADCP aiding). The navigation error is greater (up to $1 \%$ ) when the upward looking ADCP is used to track the ice overhead because it is not possible to control the misalignment angle between separately mounted upward looking ADCP and the PHINS system to better than about 0.5 degrees.

$>$ Forward looking $120 \mathrm{kHz}$ Simrad Mesotech echo sounder, with a range of $150 \mathrm{~m}$, used as a collision avoidance sensor.

$>$ Paroscientific Digiquartz $4000 \mathrm{~m}$ pressure sensor and Thales B12 GPS receiver.

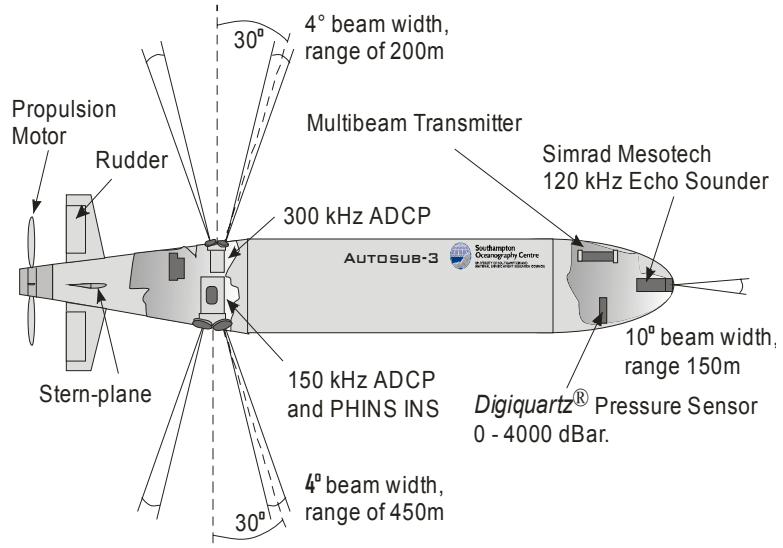

Figure 4. Sensors used for the control of Autosub3

Depth control modes can be set for any segment of the mission. They can be:

\section{$>$ Depth (constant depth)}

$>$ Altitude (constant distance from the seafloor).

$>$ UpAltitude (constant distance for the ice overhead)

$>$ Profiling (continuously profile from a lower to an upper depth, at slope angles set by the configurable pitch limits)

Safety limits, of minAlt, minUpAlt (distance above to the ice), maxDepth, and minDepth are set globally for the entire mission. These override the normal demand settings, with the 'safer' demands always being applied (e.g. the shallower of depth demand, maxDepth, and minAlt ). Where two or more safety limits conflict (e.g. an effective demanded depth resulting from the minAlt limit is shallower than the depth demand resulting from the minUpAlt), then the collision avoidance mode is triggered.

\section{The Collision Avoidance algorithm}

A detailed explanation of the collision avoidance behaviour is given in [15]. What follows is a summary and simplified account which covers the essential principles.
The collision avoidance behaviour is triggered if and only if, and for a continuous (configurable) period:

$>$ There is a conflict of depth safety limits (e.g. water column thickness is less than min_Alt+min_UpAlt) $\boldsymbol{O} \boldsymbol{R}$

$>$ The forward range to an obstacle is less than a threshold (e.g. $100 \mathrm{~m}$ ), AND the range rate is greater than a threshold (these filters were found necessary to reject spurious triggers).

Once the collision avoid mode is triggered, the AUV backtracks a (configurable, e.g. $1 \mathrm{~km}$ ) distance in the horizontal plane, while at the same time the depth limits used by the depth controller are changed to preset 'safer' limits. For example, the safer limits would typically have a deeper minDepth for under ice work (deeper than the maximum anticipated ice draft). Once backtracked, the AUV turns again and takes a random course in an attempt to try and get around the obstacle. If the collision trigger condition becomes true again, before the obstacle is cleared, then the AUV will repeat the backtrack, and try another random course. Once the obstacle is cleared, the AUV will return to its original track.

\section{Communications and Tracking.}

To secure successful operations under ice, we found that it is vitally important to have a dependable acoustic communications system. Reliability analysis indicated that the acceptable level of risk for under ice missions would only be achievable if the AUV was monitored for total of 4 hours before committing the AUV to continue its mission, and at the end of the mission it is possible that the AUV might encounter either sea ice or icebergs blown over the intended recovery position.

Hence there are requirements for simple control messages to be sent to the vehicle (such as "Continue" , "Surface", "Abort"), and status messages (polled) to be received from the vehicle. We also implemented sending of a position offset to the AUV navigation system via the acoustic telemetry link so that we could control where the AUV surfaces.

For the acoustic communications part of this system, we integrated the LinkQuest Tracklink 10000 system with the AUV control software and ship side AUV monitoring and control systems. This system conveniently combines the required short message capability with USBL tracking.

We found that on the $N B$ Palmer (not a particularly acoustically quiet ship) the USBL systems gave tracking distances of up to about $3.5 \mathrm{~km}$ horizontal displacement, with the AUV at $800 \mathrm{~m}$ depth (this is outside the manufactures recommended operating cone for the system, hence the range is less than maximum achievable with this system). But this range equates to only 40 minutes of tracking time if the AUV is heading away, and also is uncomfortably close to the magnitude of potential navigation errors if the AUV had spent a large percentage of its time without bottom track navigation. We needed a basic tracking system with more range. 
Nothing with the required performance being available commercially, we developed a low frequency beacon system for the AUV, which emits on the minute mark, a $4.5 \mathrm{kHz}$ narrow band $(40 \mathrm{~Hz})$ chirp lasting one second, at $50 \mathrm{~W}$ acoustic radiated power. In ideal deep water conditions, ranges up to $30 \mathrm{~km}$ can be achieved. Rudimentary, one way telemetry is also possible by varying the repetition period for this beacon. In default mode the beacon transmits every 10 minutes. In emergency mode (triggered by the detection of a serious malfunction, such as total power loss) it transmits at 1 minute intervals. The repetition period can be controlled from the mission script to indicate significant mission events, for example when the AUV is heading back towards the recovery position. The receiver for this beacon is a hydrophone array deployed by hand to a depth of $50 \mathrm{~m}$ below the ship (to reduce the effect of ship generated noise).

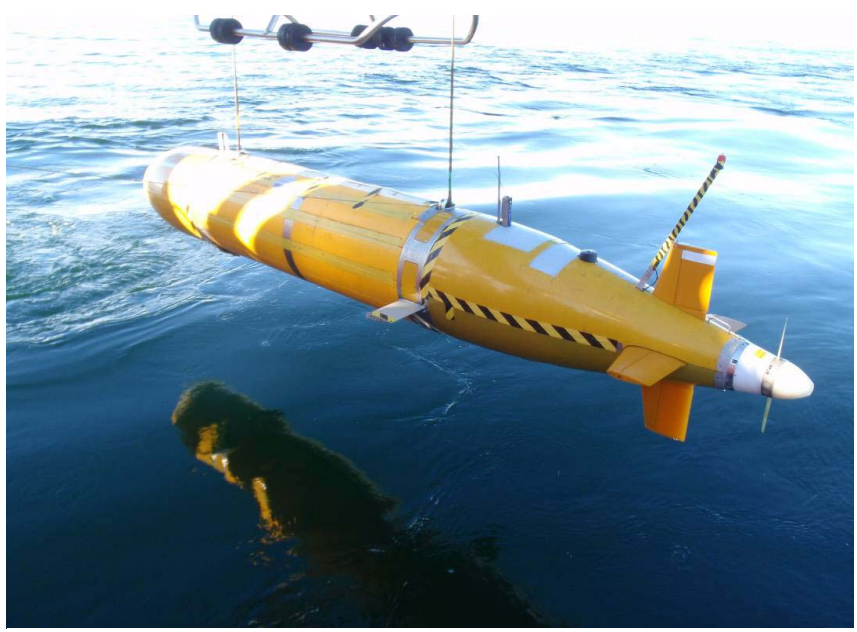

Figure 5. Autosub3 being launched at the start of its first mission under the PIG ice shelf. We were fortunate in having mostly good weather and calm seas in the polynea extending $60 \mathrm{~km}$ north of the ice front. Note the small winglets, allowing efficient operation at slow speeds, and the (white) LDPE acoustic windows on the upper side of the rear panel, for the upward looking ADCP and the EM2000 receiver.

A Simrad EM2000 multibeam sonar produces a swath bathymetric image of either the underside of the ice shelf or the seabed, depending upon the orientation of its installation on the vehicle. The swath width is $350 \mathrm{~m}$, with a resolution of approximately $3 \mathrm{~m}$ when the AUV is flying at range of $100 \mathrm{~m}$ from either the ice overhead or the seabed below.

\section{Objectives of Palmer Cruise 0901.}

In the Amundsen and Bellingshausen seas, unlike other areas around the continent coast, the ice shelves are flooded by upper Circumpolar Deep Water, which is $3^{\circ} \mathrm{C}$ warmer than the surface freezing point. When this water mass contacts the base of an ice shelf, melting rate is an order or two of magnitude higher than it would otherwise be. The data collected by the Autosub3 will help answer the question of whether the warm water and rapid melting is responsible for the currently observed thinning of the ice shelves in this region.

There are three specific objectives to the deployment of Autosub 3 under the PIG:

- To map the seabed beneath the ice shelve.

- To map the underside of the ice shelve.

- To determine where and how heat is transferred from the inflowing lower layer waters to the out flowing upper water.

The primary target was the Pine Island Glacier (PIG) Ice Shelf, at around 75 degrees South, 101 degrees West.

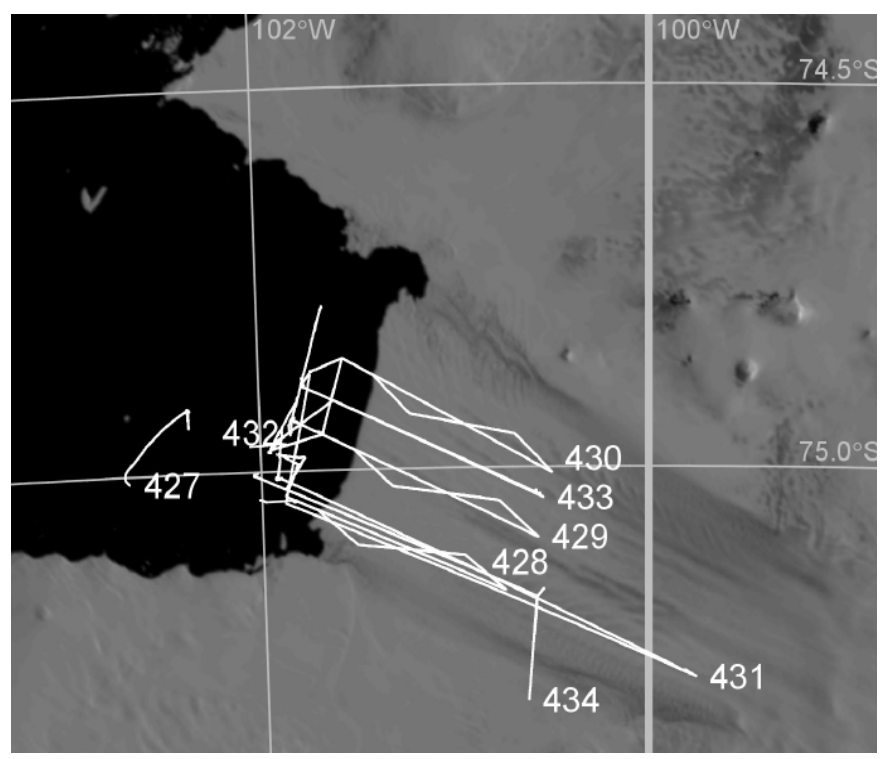

Figure 6. The tracks of all of the 8 Autosub3 missions carried out in the vicinity of the PIG in January 2009, superimposed on a recent MODIS satellite image. Missions 427 and 432 were test missions in open water.

\section{RESULTS}

\section{A) Mission Tracks and sensor data}

The USA ice breaker, the Nathaniel B Palmer, with Autosub3 onboard departed Punta Arenas on the afternoon of $5^{\text {th }}$ January 2009. Fortunately the weather was relatively kind for the crossing of the infamous Drake's passage, and the sea ice conditions north of the PIG bay did not much impede our progress. We were also pleased and relieved when we arrived in the work area on January 16th to find a large polynea extending from the ice front of the PIG. This, together with a relatively calm sea, would considerably ease our tests and operations (Fig. 5). 
The planning of the AUV missions profiles was assisted by the availability of ice thickness data, obtained by airborne radar sounding over the ice shelf, in 2006. These radar measurements, as later Autosub data showed, gave an accurate representation of the ice draft at horizontal scales greater than about $500 \mathrm{~m}$, but as it later turned out, failed to predict deep fissures in the ice shelf on scales of tens of meters wide. Based on these profiles, for the some of the missions, it was possible to set a minDepth which was deeper than the expected deepest ice draft on the mission profile, hence providing an extra level of safety.

During this first under ice shelf mission (mission 428) (and for the following two missions), the mission plan was to track the seabed at a altitude of $200 \mathrm{~m}$ into the ice cavity for $30 \mathrm{~km}$, and then to turn back and track the underside of the ice, at a distance of $100 \mathrm{~m}$, while imaging the underside of the ice shelf with the EM2000 multibeam sonar. On the way back, the track was deliberately set first north of the incoming line, then south, thereby giving better lateral coverage of the ice cavity, and avoiding the EM2000 swaths being aligned with the expected ice ridges. Mission 428 was in the southern side of the ice shelf, and the third, mission 430, at the northern end. Fig. 6 is a plan view of all the missions completed, superimposed over satellite imagery of the glacier and surrounding areas. The maximum penetration under the ice shelf was $61 \mathrm{~km}$ (during mission 431). In total, $510 \mathrm{~km}$ was run under the PIG ice shelf, over a period of 94 hours, between the $19^{\text {th }}$ January and the $31^{\text {st }}$ January 2009.

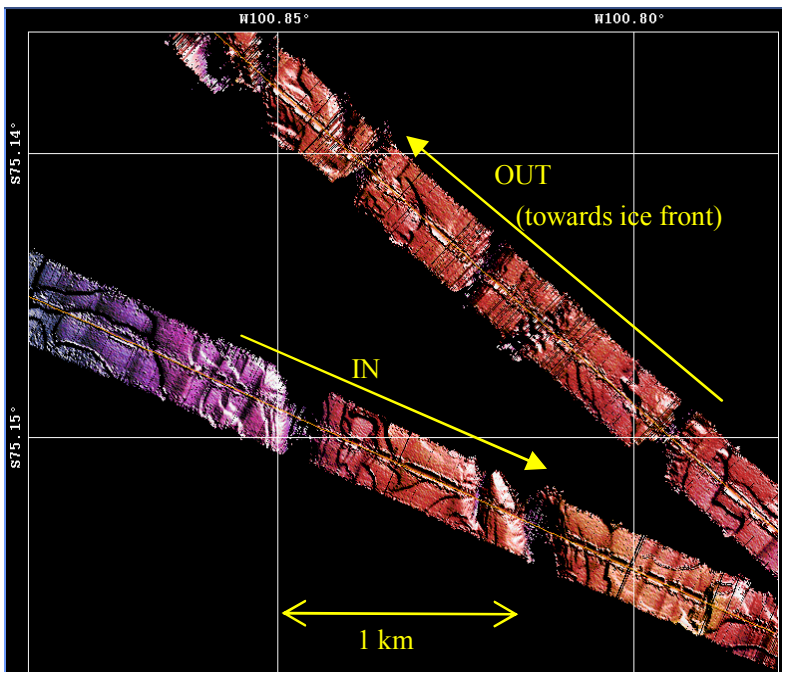

Figure 7. EM2000 imagery of the underside of the PIG ice shelf and $60 \mathrm{~km}$ in. The swath was $320 \mathrm{~m}$ wide

Fig. 7 is a small section of the EM2000 data obtained from the first mission, the multibeam looking upwards at the underside of the ice shelf. This shows the relief relative to the AUV. Such raw images were used during the cruise for engineering diagnostic purposes. The absolute depth and fully navigation corrected images are still being processed at the time of writing.
The final mission of the campaign was the most ambitious in terms of mission complexity, and serves as a useful illustration of the operational procedures, and the modes of operation and navigation (Fig. 8). The event log (Table I) gives an overview of the overheads for launch, recovery and for checking the AUV before sending it under the ice shelf.

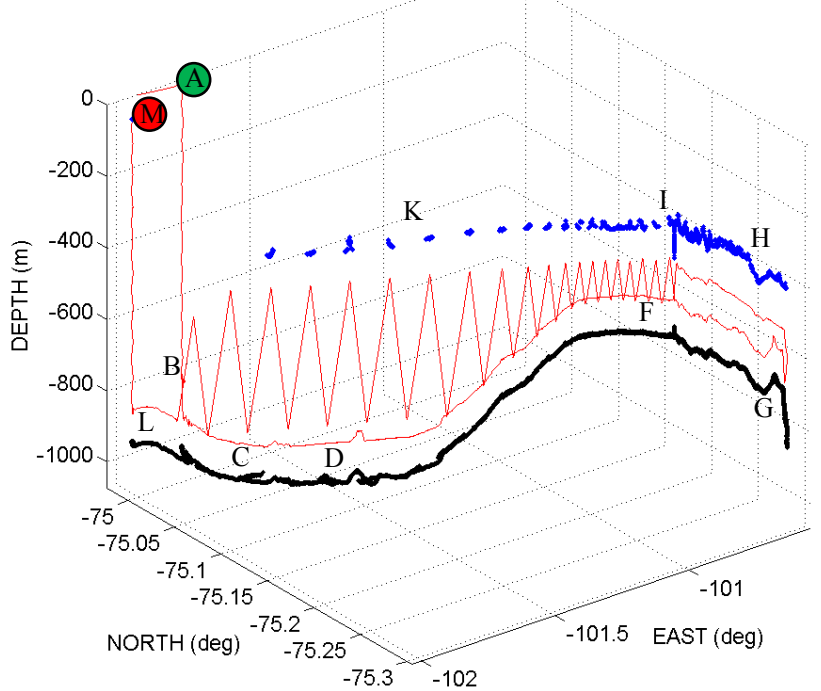

Figure 8. 3D plot of the final Autosub3 mission under the PIG. The (black) lower trace is the seabed (as detected by the $150 \mathrm{kHz}$ ADCP), the (blue) upper trace is the ice shelf (as detected by the upward looking $300 \mathrm{kHz}$ ADCP ). The vehicle entered the ice shelf at $100 \mathrm{~m}$ altitude, and left while depth profiling. Note that the vertical exaggeration of this plot is $300: 1$.

TABLE I

EVENTS DURING FOR MISSION 434 ON 30/1/2009 TO 31/1/2009

$\begin{array}{lll} & \end{array}$




\section{B) AUV Navigation performance}

Because of the unusual navigation capability of Autosub3, using an upward as well as downward looking ADCP, capable of Doppler navigating relative to the seabed or the ice, it is interesting to consider the navigation performance of the vehicle.

The navigation drift (as measured by the difference in position between the dead reckoned position and the GPS position when the AUV surfaces at the end of a mission), was highly variable between missions, with drift rates ranging from $0.025 \%$ (m per $100 \mathrm{~m}$ travelled), to $1.6 \%$. Three missions $(3,4,5)$ gave errors of less than $0.1 \%$ (Table II). These had the shortest periods of ice tracking. The implication is that the ice tracking mode of navigation was less accurate than water tracking mode (or in effect the currents experienced). On the first mission, the ascent rate at the end of the mission was particularly long (1 hour longer than the later missions), due to an un-powered ascent mode. This seems to be correlated with a particularly bad navigation drift performance, presumably due to the effect of currents as it ascended.

TABLE II

NAVIGATION DRIFT RATE AND NAVIGATION MODES

\begin{tabular}{l|lllllll}
\hline$\#$ & $\begin{array}{l}\text { Total } \\
\text { (hrs) }\end{array}$ & $\begin{array}{l}\text { Bed } \\
\text { Track- } \\
\text { ing } \\
\text { (hrs) }\end{array}$ & $\begin{array}{l}\text { Ice } \\
\text { Track- } \\
\text { ing } \\
\text { (hrs) }\end{array}$ & $\begin{array}{l}\text { Water } \\
\text { Track- } \\
\text { ing } \\
\text { (hrs) }\end{array}$ & $\begin{array}{l}\text { Nav. } \\
\text { error } \\
\text { North } \\
(\mathrm{m})\end{array}$ & $\begin{array}{l}\text { Nav. } \\
\text { error } \\
\text { East } \\
(\mathrm{m})\end{array}$ & $\begin{array}{l}\text { Nav } \\
\text { error }\end{array}$ \\
\hline 1 & 16.1 & 12.1 & 1.6 & 2.4 & -111 & 1428 & 1.6 \\
2 & 16.8 & 13.3 & 2.5 & 1.0 & 420 & -88 & 0.46 \\
3 & 19.0 & 18.3 & 0.01 & 0.6 & -40 & -63 & 0.07 \\
4 & 34.5 & 32.9 & 0.06 & 1.5 & -45 & 15 & 0.02 \\
5 & 30.4 & 29.5 & 0 & 0.9 & 50 & -141 & 0.09 \\
6 & 33.6 & 30.6 & 0.6 & 2.4 & -262 & -435 & 0.28 \\
\hline
\end{tabular}

\section{C) Autosub Mission 341 - A close scrape.}

Not all went perfectly according to plan. Following the successful completion of 3 missions (each of $30 \mathrm{~km}$ into the ice shelf, starting at the south, mid and north sides of the ice shelf), the fourth mission was planned to be more ambitious, travelling $60 \mathrm{~km}$ or more in towards the ice shelf grounding line. On $24^{\text {th }}$ January Autosub3 was launched for its fourth mission. Thirty six hours later, the AUV was recovered onto the N B Palmer. It was only as Autousb3 was being lifted out of the water did we notice that the mission had been 'eventful'. There was significant damage to the port and starboard front section fibre glass fairings. The small winglets were damaged and bent back on both sides (its interesting to note that these small aluminium section wings almost certainly saved the vehicle from total loss, by protecting the much more fragile sternplanes $-\mathrm{a}$ fortunate but unintended design feature).

The AUV had been programmed to head towards the grounding line on the south side of the ice shelf. It was not expected that Autosub3 would be able to reach the given waypoint, and would turn around as programmed when the water column thickness became less than $200 \mathrm{~m}$. This occurred as expected, and as programmed the AUV then ascended up towards the ice shelf. The plan was that it would track the ice shelf, at a range of $100 \mathrm{~m}$. This is where it got into severe difficulties. Fig. 9 illustrates the problem.

For the first three missions it had been possible to set a 'minDepth' (minimum depth), which, while allowing the ice base to be successfully imaged with the multibeam sonar, protected the AUV from ascending too far into any ice fissures. This protection was feasible for these missions up to $30 \mathrm{~km}$, because the ice base had relatively constant draft. But this extra layer of safety was not available for us for the longer run into the cavity, because the ice draft increased significantly from $500 \mathrm{~m}$ up to $1000 \mathrm{~m}$ as the AUV approached the grounding line.

Hence the AUV was totally dependent upon the returns from the upward looking ADCP for avoiding collision with the ice. Unfortunately the ice was so deeply fissured at the turning point (presumably due to strains set up near the grounding line), that there were insufficient sonar returns for the AUV to successfully control its hold off distance from the ice.

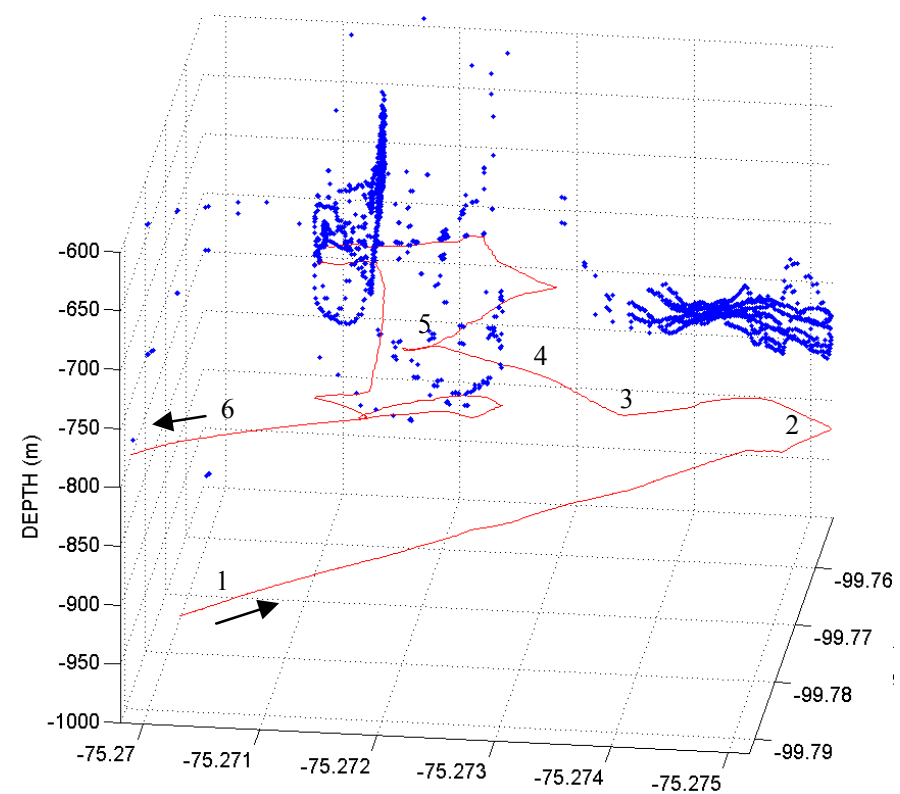

Figure 9. Autosub3 collision with the PIG ice shelf.

The continuous trace is the vehicle track, and the (blue) dots are all the returns from the four beams of the upward looking $300 \mathrm{kHz}$ ADCP (the seabed is not shown on this plot). At (1) the AUV is entering toward the grounding line; at (2) the AUV turns as planned when the water column thickness becomes less than $200 \mathrm{~m}$, and is controlling normally - there are solid returns on all four beams; at (3) the returns become sporadic, and the AUV climbs steeply, at (4) the AUV's course is translated to starboard by hitting ice on its port side, but no collision was detected; (5) the AUV detects a collision and turns back, only to remain in contact with the ice, and turns back and forward several times, but still not getting consistent returns from the ice; finally the AUV dives as the emergency script is triggered by a 'collision failed' timeout and (6) the AUV continues back towards the recovery position $70 \mathrm{~km}$ away.

Consequentially it ascended into a deep fissure. The collision avoidance algorithm was invoked, but unfortunately too late to avoid impact. Trapped in ice fissures the AUV retreat and try again strategy was not very effective. In all it took over 30 
minutes of scraping and bumping for the AUV to get out of trouble, eventually diving down and clearing the ice when a timeout event 'collision avoid failed' occurred, and the mission control executed an emergency mode mission script which commanded the vehicle to dive then run the $70 \mathrm{~km}$ to the recovery position while flying at mid water level (Fig. 9).

\section{IV-CONCLUSIONS}

The PIG under ice campaigns using Autosub3 on the N B Palmer demonstrated that it is possible to operate an AUV with sufficient capabilities of endurance, navigation, collision avoidance, and most of all reliability, to gather data in an environment which is otherwise completely inaccessible.

These capabilities did not come cheaply, but was the culmination of an effort on the part of the NOC engineers over fifteen years. Important to the success was the continuity of funding, keeping the engineering team together, and the combined technology development and science missions during the Autosub Under Ice and Autosub Science Mission programmes.

The successful missions also illustrates the benefits of international cooperation, with the UK (NERC through NOCS) providing the AUV and the USA (NSF) providing the host ship. It is to be hoped we can build on these achievements and collaborations in the future (with an improved collision avoidance system installed on the AUV) with further, longer and deeper explorations underneath polar ice shelves.

\section{ACKNOWLEDGMENT}

We thank the cruise chief scientist, Dr. Stan Jacobs, the captain, crew, sailors and Raytheon technical support team of Nathaniel B Palmer 0901 who so professionally helped us achieve our goals during the cruise.

\section{REFERENCES}

[1] R.E. Francois, and W.E. Nodland, "Unmanned Arctic research submersible (UARS) system development and test report", Washington, $A P L$-UW Report 7219: 87.

[2] J.H. Morison, and M.G McPhee, "Lead convection measured with an autonomous underwater vehicle," J. of Geophysical Research, 103(C2), pp. 3257-3282, Feb 1998.
[3] D.R. Hayes, and J. H. Morison, 2002, "Determining Turbulent Vertical Velocity, and Fluxes of Heat and Salt with an Autonomous Underwater Vehicle," J. of Atmospheric and Oceanic Technology, vol. 19, pp. 759779 .

[4] J. Ferguson, A. Pope, B. Butler, and R. I. Verrall, (1999)., "Theseus AUV - two record breaking missions", Sea Technology, vol. 40, no. 2, pp. $65-70$.

[5] P. Wadhams, J. P. Wilkinson, and A. Kaletzky, "Sidescan Sonar Imagery of the Winter Marginal Ice Zone Obtained from and AUV", $J$. of Atmospheric and Oceanic Technology, vol. 2, no. 9, pp. 1462-1470, 2004.

[6] R. McEwen, H. Thomas, D. Weber, and F. Psota, "Performance of an AUV navigation system at Arctic latitudes," IEEE J. of Oceanic Engineering, vol. 30, no.2, pp. 443-454, April 2005.

[7] C. Kunz, C. Murphy, R. Camilli, H. Singh, J. Bailey, R. Eustice, M. Jakuba, K. Nakamura, C. Roman, T. Sato, R. Sohn, and C. Willis, "Deep sea underwater robotic exploration in the ice-covered Arctic ocean with AUVs," IEEE/RSJ International Conf. on Intelligent Robots and Systems, IROS, pp.3654-3660, 22-26 Sept. 2008.

[8] A.S. Brierley, P.G Fernandes, M.A. Brandon, F. Armstrong, N.W. Millard, S.D. McPhail, P. Stevenson, M. Pebody, J.R. Perrett, M. Squires, D.G. Bone, and G. Griffiths, "Antarctic krill under sea ice: elevated abundance in a narrow band just south of ice edge", Science, vol. 295, pp. 1890-1892, 2002.

[9] P.J. Wadhams, J.P. Wilkinson, and S.D. McPhail, "A new view of the underside of Arctic sea ice", Geophysical Research Letters, vol. 33, L04501, 2006.

[10] K.W. Nicholls, E.P. Abrahamsen, J.J.H. Buck, P.A. Dodd, C. Goldblatt, G. Griffiths, K.J. Heywood, N.E., Hughes, A. Kaletzky, G.F Lane-Serff,. S.D. McPhail, N.W. Millard, K.I.C. Oliver. J. Perrett, M.R. Price, C.J. Pudsey, K. Saw, K. Stansfield, M.J. Stott, P. Wadhams, A.T. Webb, and J. P. Wilkinson, "Measurements beneath an Antarctic ice shelf using an autonomous underwater vehicle", Geophysical Research Letters, vol. 33, no. 8, L08612 10.1029/2006GL025998, 29 April 2006.

[11] J. Strutt, (editor), "Report of the inquiry into the loss of Autosub2 under the Fimbulisen", NOCS Research and Consultancy Report available as a pdf at http://eprints.soton.ac.uk/41098/.

[12] G. Griffiths, and A. Trembanis, "Towards A Risk Management Process For Autonomous Underwater Vehicles," in Proceedings of the Masterclass in AUV Technology for Polar Science, G. Griffiths and K. J. Collins, eds. London, Society for Underwater Technology, 2007, pp. 146.

[13] S. Heath, "Echelon Networking Control," IEE Review, vol. 38, pp. 10-14, 1992.

[14] S. D McPhail, and M. Pebody, "Navigation and Control of an Autonomous Underwater Vehicle Using a Distributed, Networked, Control Architecture", J. of the Society for Underwater Technology, vol. 23, pp. 19-30, 1998.

[15] M. Pebody, "Autonomous underwater vehicle collision avoidance for under-ice exploration," Proc. IMechE, Part M: J. Engineering for the Maritime Environment, vol. 222, pp. 53-66, 2008. 